\title{
Lifestyle Associated with Caregiver Burden of the Elderly
}

\author{
Addy Elena Hernández Damas ${ }^{1}$, Claudia Leticia Puga Cahuich ${ }^{2}$ and Guillermo Padrón Arredondo ${ }^{3 *}$ \\ ${ }^{1}$ Department of Nursing, General Hospital Playa del Carmen, Mexico
}

${ }^{2}$ Academic Division of Health Sciences, Autonomous University of Tabasco. Villahermosa, Tabasco, Mexico

${ }^{3}$ Department of Surgery, General Hospital Playa del Carmen, Mexico

Submission: April 05, 2018; Published: April 12, 2018

*Corresponding author: Guillermo Padrón Arredondo, Department of Surgery, General Hospital Playa del Carmen, Mexico,

Email: gpadronarredondo@hotmail.com

\begin{abstract}
Objective: Analyze the relationship between lifestyle and level of caregiver burden of older adults with chronic illness.

Material and Method: quantitative, observational, descriptive, transversal study. The sample consisted of 57 caregivers of elderly or dependent adults with chronic disease. The sampling was non-probabilistic for convenience.

Results: It was found that caregivers with greater burden were $14.03 \%(\mathrm{n}=9)$, mild overload the $14.03 \%(\mathrm{n}=9)$, without overloading the $71.92 \%(n=43)$. Rates lifestyle of caregivers of elderly ranged between 24.85 and $62.31 \%$, the lowest rate was obtained by the exercise dimension and the highest rate was personal growth.

Discussion: These data are different from those reported by Alducin, et al., who reported that the dimension with the lowest score was responsibility for health and greater personal growth with 28.3 and 41.2 respectively. Dimensions deficiency responsibility in health, stress management and exercise contribute to the lifestyle of elderly caregiver disease-oriented rather than promoting health.
\end{abstract}

Conclusion: In the study they prevailed without overloading caregivers, followed by caregivers with intense overload which poses a possible relationship with the dimensions of lifestyle that are smaller dimension; stress management and lack of exercise performance.

Keywords: Lifestyle; Caregiver burden; Burnout; Elderly; Chronic illness

\section{Introduction}

According to the National Population Council (CONAPO), in Mexico there are 11.7 million people over 60 years of age, representing $9.7 \%$ of the total population, according to projections for 2014 , of which $31.5 \%$ are in a stage of pre-age (60 to 64 years); $41.1 \%$ are in a functional old age (65 to 74 years); $12.3 \%$, in full old age (75 to 79 years), and $15.1 \%$ transited through advanced age ( 80 years and over) and as age increases, deterioration of health becomes evident, disease, disability and dependence in care [1-3].

Old age causes various health impairments, some of which lead to greater disability. The state of physical and mental health of older adults differentiate the care they require, it is not the same as the old man wanders and retains even the minimum independence for the basic activities of daily life, dependent and requires the dependent care of another person whose diversity will be mediated by the physical state and may increase [4]. The affectation experienced by the caregiver and the feeling that his life has changed unfavorably from the care of the elderly is summarized in the concept of "burden." A person is considered a caregiver if he or she cares for an elderly person in their home regardless of whether they receive remuneration or degree of relationship. The caregiver will overload the tasks required by the dependent person at the cost of reducing the social relationships so necessary to maintain an acceptable level of mental health, a style that was defined in 1999 by the World Health Organization, WHO, as: "one composed of his habitual reactions and the patterns of behavior that he has developed during his socialization processes over time", affects the personal character of the caregiver. In turn, taking on new activities to replace the functions performed by the person and adapt to a new lifestyle creates stress in the caregiver [5]. It is therefore important to identify the caregivers' lifestyles of older adults and their influence on the overload, since it is considered a predictor of the quality of the care given to the elderly, which will allow propose and implement intervention strategies in caregivers who favor their lifestyle and, therefore, reduce the burden [6].

Domínguez Sosa et al. [7] found, from the qualitative point of view, the factors associated with the perception of stress, 
the number of functions performed in the role of caregiver, suspended activities of daily life, optimism, and own perception of the quality of the caregiver-patient relationship. On the other hand, from a quantitative perspective, factors associated with overload syndrome, the history of depression in the caregiver, the presence of illness in the caregiver, and the perception of family functionality has been described. Da Silva MJ et al. [8] found that family caregivers of dependent elderly people resemble the characteristics consecrated in the literature: the majority is women, daughters, without own income, low education and resident in the same house as the elderly. They understand care as a job because of their assumed responsibilities. The caregivers studied present indicatives of Burnout Syndrome, mainly in the aspects "emotional exhaustion" and "depersonalization". In the "work at work" aspect they presented positivity, indicating that care provided by relatives has positive factors such as affection, self-giving, faith and transcendence, aspects that are not present in professional care, whose links are limit the moral and professional aspects of each.

Cardona D et al. [9] found as associated factors: age and relationship to the older adult, number of children, daily hours dedicated to care, health status, abandonment or reduction of activity by care, reasons, needs and help received from his family; as protective factors were identified: independence and the good or regular state of health of the elderly. Hernández Zamora et al. [10] observed in their study that the Burnout level is intimately linked to the caregiver's perception of overload; when correlating both variables, found a statistically significant relationship between people suffering from elevated Burnout and rated with slight perceived overload. On the other hand, they observed that it is precisely the same variables that affect either a high level of Burnout or a level of slight overload. Nursing staff practice a profession that favors the conditions for the development of occupational stress and burnout, which is also observed in the quartermaster staff, who, at the same time as performing their own activities, helps nurses in the most onerous tasks for the care of nursing home residents, which explains that it is even greater in them than in nurses (although without statistical significance) the perceived overload as caregivers. Vázquez García C et al. [11] report that Burnout Syndrome is present in a high percentage of caregivers of older adults, being the personal realization the most affected area as well as lower salary higher frequency of Burnout Syndrome.

\section{Method}

Table 1: General and overall lifestyle indices by 57 elderly caregivers.

\begin{tabular}{|c|c|c|c|c|c|}
\hline Variable & Minvalue & Maxvalue & Mean & Median & SD \\
\hline General index & 142 & 519 & 291.2 & 280.09 & 100.214 \\
\hline Index of responsibility in health & 11 & 100 & 53.35 & 51.85 & 22.188 \\
\hline Exercise Index & 0 & 100 & 24.85 & 16.67 & 24.142 \\
\hline Nutrition Index & 15 & 89 & 48.34 & 44.44 & 17.574 \\
\hline Personal Growth Index & 22 & 100 & 62.31 & 62.96 & 23.3 \\
\hline Index of Interpersonal relations & 22 & 100 & 54.97 & 51.85 & 21.446 \\
\hline Stress Management Index & 13 & 96 & 47.37 & 45.83 & 19.169 \\
\hline
\end{tabular}

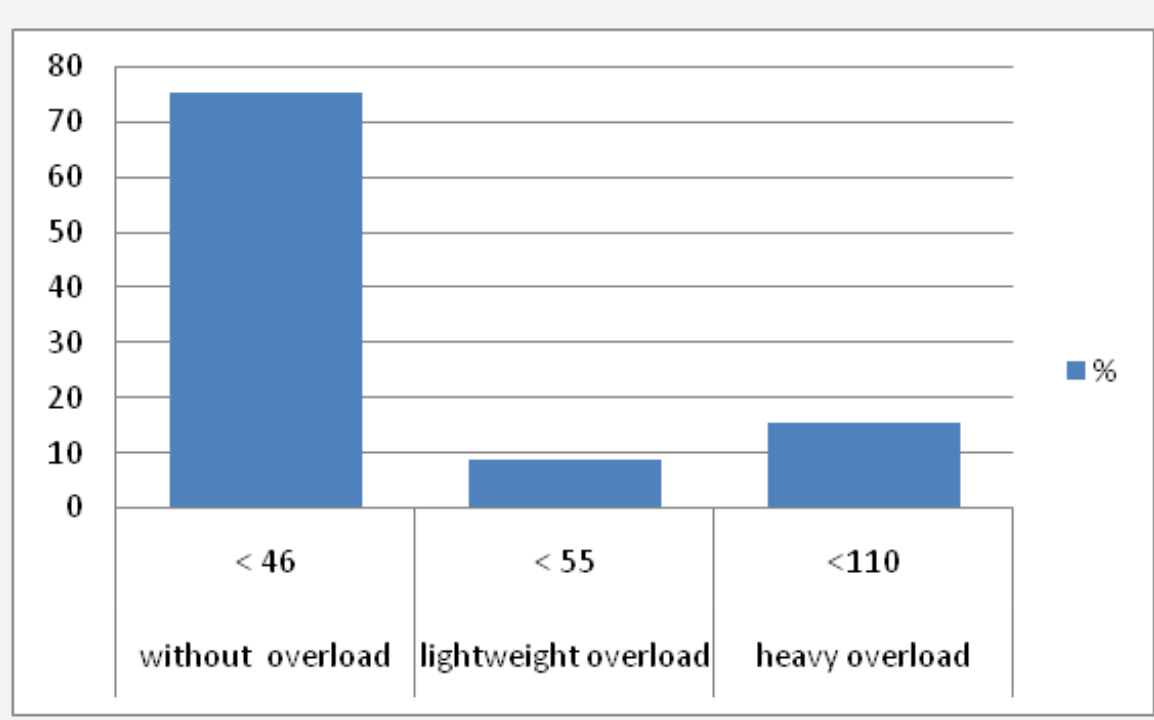

Figure 1: Profile of the lifestyle of 57 elderly caregivers. 
In order to know the relationship between lifestyle and its impact on the overload of caregivers of older adults, a descriptive (observational), transversal study was carried out. The sample consisted of 57 caregivers of elderly adults with chronic or dependent diseases. Sampling was non-probabilistic for convenience. Measurement of the variables included the Zarit Zarit Overload Scale (Table 1) and the Nola Pender PEPS II Health Promoter Style Assessment Scale questionnaire (Figure 1 ), as well as the Spearman association test of the overload of the caregiver of the elderly with chronic illness and the dimensions of the lifestyle. The study was conducted in accordance with the ethical considerations of the Regulation of the General Law on Health in the Field of Research. Statistical analysis of the data was descriptive and inferential through the statistical program SPSS version 22, Windows. The information collected was analyzed by measures of frequency, central tendency, percentages and standard deviation.

\section{Results}

The mean age of the participants was 47.42 years (SD \pm $15,177)$, the minimum age was 20 and the maximum was 88 years. The population consisted of 61 caregivers $(100 \%)$, of whom $84.2 \%(n=48)$ were female and $15.8 \%(n=9)$ were male. In this population, the predominant socioeconomic level was $53.6 \%$ ( $n=30)$, followed by the medium with $47.4 \%(n=27)$, and the primary level of schooling was $84.2 \%(n=22)$. As regards kinship, it was found that the highest percentage of caregivers correspond to the children (s) $57.9 \%(n=33)$, followed by the spouse (a) of the older adult with $24.6 \%(n=14)$. The average daily work hours of the caregivers was 20.11 hours (SD \pm 6.737 ), which could be related to the occupation of the caregivers, since $57.9 \%(n=33)$ is dedicated to housework, followed by $19.3 \%(n=11)$ of hired caregivers. According to the analysis of the information obtained, the caregivers have an average of 9.3 years of experience, and $45.61 \%$ of the elderly had two or more diseases, including Diabetes mellitus 2 (DM2) with $26.31 \%$, followed by arterial hypertension with $19.29 \%$.

The Zarit Zarit scale questions are described according to the responses of each of the sample careers. Regarding the question do you feel that your family member is asking for more help than you really need? $31.6 \%(n=18)$ responded that almost always, $28.1 \%(n=16)$ never and $17.5 \%(n=10)$ quite a few times.

The reactants that showed the greatest affectation in the participants were: in item 1, do you feel that your family member requests more help than you really need? Responded 31.6\% (n $=18)$ almost always and $28.1 \%(n=16)$ never. In reagent 7 , do you feel fear for the future that awaits your relative? $49.1 \%$ ( $\mathrm{n}=$ $20)$ answered that almost always and $17.5 \%(n=10)$ never. In reagent 8 do you think your relative is dependent on you? $43.9 \%$ $(n=58)$ almost always and $26.3 \%(n=15)$ never. In the rest of the replies of the scale, it was obtained that the caregivers presented higher scores in item 14. Do you think that your family member expects you to be the caregiver, as if you were the only person you can count on? 52.6\% ( $\mathrm{n}=30)$ almost always, while 7.0\% ( $\mathrm{n}=4)$ coincided quite often, sometimes and rarely, being $26.3 \%(n=15)$ never.

In item 15 do you think you do not have enough money to care for your relative in addition to your other expenses? 38.6\% $(\mathrm{n}=22)$ responded that almost always, $31.6 \%(\mathrm{n}=18)$ never. In item 20 do you feel that you should do more than you do for your relative? $25.6 \%(\mathrm{n}=2)$ almost always; $22.8 \%(\mathrm{n}=13)$ never. In item 21 do you think you could take better care of your relative? 45.6\% ( $\mathrm{n}=26)$ almost always and 19.3\% ( $\mathrm{n}=1)$ never. Finally, item 22, globally; how much burden do you experience for caring for your relative? 33.3\% ( $n=19)$ sometimes and $28.1 \%(n=16)$ almost always. The scores of each participant were estimated individually and grouped for the sample. Scores were then scored based on the scale criteria. The results show that caregivers with intense overload were $15.79 \%(\mathrm{n}=9)$, mild overload $8.77 \%(\mathrm{n}=$ 9), and without overload 75.44\% ( $\mathrm{n}=43)$ (Figure 1).

In the Health Responsibility dimension, the reagent 45. Do I attend educational programs on personal health care? We obtained $59.6 \%(n=34)$ responded never, followed by reagent 9 , do I read or watch TV shows about health improvement? With 50.9\% (n = 29) at some times. Does reagent 39 and 46 ask information from health professionals about taking good care of me? I am looking for guidance or advice when necessary? Respectively, caregivers responded that they routinely did $43.9 \%(n=25)$. In the physical exercise dimension, it was observed that the items with the highest score were: the reagent 14 , do I examine my pulse when I am doing exercises? $70.2 \%(n=40)$ participants responded that they never did. Following question 10, do I do vigorous exercises for 20 or more minutes, at least three times a week (such as fast walking, cycling, aerobic dancing, using the escalator)? 61.4\% (n $=35$ ), in which caregivers responded that they never carry out such activities. In addition, $61.4 \%(n=35)$ never have a planned exercise plan.

In the nutrition dimension, it was obtained that the reactants with the highest score were item 20 Do you eat 2 to 4 servings of fruits every day? $49.1 \%(n=28)$, in which participants responded that they do sometimes, followed by reagents 14 and 32 Do you eat 6 to 11 servings of bread, cereal, rice or pasta (noodles) every day? Ingests 2 to 3 servings of milk, yogurt, or cheese each day? In both reagents, $47.4 \%(n=27)$ were obtained, where the participants reported several times. In the personal growth dimension, it was observed that the items with the highest score were: the reagent 18 Do I look forward to the future? In which $50.9 \%(n=29)$ were obtained, the patients responded routinely. Also, in reagent 24 Do I feel satisfied and at peace with myself? The same score was obtained as in reagent $18,50.9 \%(n=29)$, the caregivers reported doing so routinely. In reagent $42 \mathrm{Am}$ I aware of what is important to me in life? $49.1 \%(n=28)$ responded that they are routinely. In the interpersonal relationships dimension, it was found that the items with the highest score were the reactive 25; does it make it easy for me to show concern, love and affection to another? 
42.1\% ( $\mathrm{n}=24)$, respondents reported doing so routinely. In item 49; do I agree with others through dialogue and commitment? $42.1 \%$ ( $\mathrm{n}=24$ ) reported routinely. Also, in item 13 do I maintain meaningful and enriching relationships? $40.4 \%(n=23)$ said to do so routinely. By last; in the stress management dimension, it was found that the reactants with the highest percentage were item 17; Do I accept those things in my life that I cannot change? $61.4 \%$ $(\mathrm{n}=35)$ responded that they do it routinely, followed by item 20 Do I use specific methods to control my stress? 50.9\% $(n=29)$ in which caregivers reported never to do so. Finally, in item 41 do I practice relaxation or meditation for 15-20 minutes daily, $49.1 \%$ $(\mathrm{n}=28)$ of participants responded never do so.

Table 1 shows the indices obtained by dimensions. The primary caregivers of this study have as their primary objective personal growth with an average of 62.31 ( $S D \pm 23.300$ ); secondly, there are interpersonal relationships with a mean of 54.97 $(\mathrm{SD} \pm 21.446)$ and thirdly the responsibility in health with an average of $53.35(\mathrm{SD} \pm 22.188)$.

Table 2 shows that, when correlating the overload with the caregiver's lifestyle, there is a negative association ( $r$ ho $=-.108, \mathrm{p}$ $=.422$ ), so it is deduced that the higher overload caregivers' lives. Also, when correlating the caregiver's overload with the global lifestyle and dimensions, a negative association (rho $=-0.272, p=$ .040) was found in the personal growth dimension, which allows us to infer that the presence of overload in the caregivers affects the personal growth of them, that is, to greater overhead less personal growth. In the nutrition dimension we found negative association (rho $=-107, \mathrm{p}=.430$ ), that is to say, the higher the caregiver the less care will lend to his nutrition. Positive association (rho = 199, p = .138) was found in the personal growth dimension, which allows to relate that the lower the caregiver's higher the interpersonal support of the same. This was also observed in the management dimensions of the stress ( $r h o=157, p=.243$ ) and exercise (rho $=150, \mathrm{p}=.266$ ), i.e., at lower overload, the caregivers presented better stress management and greater participation in exercise.

Table 2: Spearman's association test of elderly caregiver overload with chronic disease and lifestyle dimensions of 57 elderly caregivers.

\begin{tabular}{|c|c|}
\hline 1. Caregiver Overload Score & -1 \\
\hline 2. Lifestyle Score & $-.108(p=.422)$ \\
\hline 3. Health responsibility & $.024(p=.862)$ \\
\hline 4. Exercise & $.150(p=.266)$ \\
\hline 5. Nutrition & $-.107(p=.430)$ \\
\hline 6. Personal growth & $-.272^{*}(p=.040)$ \\
\hline 7. Interpersonal support & $199(p=.138)$ \\
\hline 8. Stress management & $157(p=.243)$ \\
\hline
\end{tabular}

\section{Discussion}

Most careers taking responsibility for the sick are ignorant of the burden and the implications of caring. The caregiver progressively increases the time of care for the person and decreases the rest time for him with a tendency to overprotection, which implies more time, work and dedication, facing the risks associated with stress and / or exhaustion, thus changing the style their life style on the quality of care they older adults. The high levels of overload of the caregiver are closely related to the lifestyle that it takes and in turn is reflected in the way in which it provides the care that the elderly elder requires and in the improvement of it. Caring involves effort and responsibilities on the part of the caregiver as well as modifications in their lifestyle that has been seen that influence the degree of burden / overload that develops. The affectation experienced by the caregiver and the feeling that his life has changed unfavorably is summarized in the concept of "burden" [12]. Flores et al. [13] studied 67 caregivers, 6 of 10 had intense overload (59.7\%). They were mostly caregivers who dedicated a large amount of daily hours to care provoking an incompatibility between the accomplishment and fulfillment of work outside the home and the care of the elderly, i.e. the impact of their lifestyle on care led to overload [14]. In this study it was found that the highest percentage of caregivers corresponded to the female sex and was engaged in housework, these data are similar to those described by Díaz et al. [15]. because in its study the predominant population corresponded to the female sex with less than 60 years. The family member in whom care was given was in children, followed by the spouse of the older adult; these sociodemographic data obtained the highest percentages as in a study by Rivera, et al.16 in which $73 \%$ of the caregivers were the patient's children, that is, the children are caring for their parents. The average number of hours worked per day was 20.11 hours with a 9-year average caregiver experience. Previous studies report similar characteristics in caregivers of older adults, since they point out that caregivers dedicate 24 hours a day to this task, however, they have an average experience of 1 to 5 years. Camacho et al. [6] Flores et al. [13] In our study, older adults had two or more diseases, including Diabetes mellitus 2, followed by high blood pressure. Vicente de la Cruz et al. [14] in their study found that the elderly care recipients presented Diabetes mellitus type 2 in 30.9\% and Hypertension in 19.5\%.

Regarding the overload of caregivers, other authors have reported that $5.8 \%$ of caregivers presented it. In turn, Rivera et al. [16] found $14 \%$ of mild overload and $11 \%$ with overload. The lifestyle of elderly caregivers was identified through the indices of the six dimensions, where the means ranged from 24.85 to $62.31 \%$, the lowest index was obtained from the exercise dimension and the dimension with the highest index was personal growth. These data are different from those reported by Alducin et al. [17] who reported that the dimension with lower score was responsibility in health and the highest score was personal growth with 28.3 and 41.2 respectively. Studies in this regard confirm this tendency of the overload in the caregivers which becomes manifest in this work [18-23]. On the other hand, deficiency in the dimensions of health responsibility, stress management and exercise contribute to a poor elderly caregiver's lifestyle. Undoubtedly, the role of the nursing staff and the family in the care of the older adult takes on a very important dimension that it is necessary to reinforce 
with all the means with which this segment of the population has a dignified life [24-26]. As in our study, De Valle-Alonso MJ et al. [27] report that overload and Burnout syndrome in family caregivers were found to be low. The factor related to overload and burnout was the daily time spent on care. Based on the results, it is proposed to establish preventive training programs on care directed to the relatives of the elderly in order to contribute to the well-being of caregivers.

Resilience is the ability to overcome adversity, recovers, and emerges strengthened, successful and develops social, academic and vocational competence, despite being exposed to severe psychosocial stress. Protective factors that promote resilient behavior come from three possible sources:

a) Personal attributes such as intelligence, self-esteem, ability to solve problems or social competence;

b) The support of the family system; and

c) Social support derived from the community.

Menezes de LucenaCarvalho et al. [28] investigated in Formal Caregivers the relation between Resilience and negative and positive mental aspects of psychological well-being (BurnoutEngagement). The instruments used were: Connor-Davidson Resilience Scale, Maslach Burnout Inventory-General Survey and Utrecht Work Engagement Scale. The most significant findings showed that caregivers with high scores on Resilience, compared to the low scores, obtained higher levels of efficacy and engagement (Engagement), and exteriorized less emotional exhaustion and cynicism. It cannot be concluded that the most resilient caregivers do not get burned (Burnout), but they achieve greater skills and competences of work commitment (vigor, dedication and absorption), and to the extent that they reinforce these personal attributes, they mitigate the vulnerability to Burnout.

\section{Conclusion}

In this study, caregivers prevailed without overload; but the lack of strategies for stress management and lack of exercise were evidenced. Protective factors of caregivers that favor Resilience should be promoted and this study strengthens the possible scope of nursing as a social support and cushion of caregiver overload and the idea of the need to improve the care plan for elderly caregivers, also confirms the importance of having institutions that provide support to caregivers who implement strategies in favor of caregiver and care recipient.

\section{References}

1. Giraldo Osorio, Alexandra, Toro Rosero, María Yadira, Macías Ladino, et al. (2010) La promoción de la salud como estrategia para el fomento de estilos de vida saludable. Hacia la Promoción de la Salud 15(1): 128143.

2. Contreras C (2011) Estilos de vida Promotores de la Salud en trabajadores de una plataforma marina. Ciencia y trabajo 13(41): 181186.
3. Espín Andrade, Ana Margarita (2012) Factores de riesgo de carga en cuidadores informales de adultos mayores con demencia. Rev Cub Salud Públ 38(3): 393-402.

4. Baster J (2012) Adultos mayores en funciones de cuidadores de ancianos. Rev Cub Salud Púb 38(1): 168-173.

5. Valer Daiany Borghetti, Aires Marinês, Fengler Fernanda Lais, Paskulin Lisiane Manganelli Girardi (2015) Adaptación y validación del Inventario de Sobrecarga del Cuidador para uso en cuidadores de ancianos. Rev Latino Am Enfermage 23(1): 130-138.

6. Camacho L, Yokebed Hinostrosa G, Jiménez A (2010) Sobrecarga del cuidador primario de personas con Deterioro Cognitivo y su relación con el tiempo de cuidado. Rev Enferm Univ 7(4): 35-41.

7. Domínguez Sosa G, Zavala González MA, De la Cruz Méndez D del C, Ramírez Ramírez MO (2010) Síndrome de sobrecarga en cuidadores primarios de adultos mayores de Cárdenas, Tabasco, México. Méd UIS 23(1): 28-37.

8. Da Silva MJ, Braga Marques M, Da Silva Bruno CT (2009) Evaluación de la presencia del Síndrome de Bournout en cuidadores de ancianos. Enferm Glob 16: 1-11.

9. CARDONA A, Doris, SEGURA C, Ángela M, BERBESI F, et al. (2013) Prevalencia y factores asociados al síndrome de sobrecarga del cuidador primario de ancianos. Rev Fac Nac Salud Púb 31(1): 30-39.

10. Hernández Zamora ZE, Ehrenzweig Sánchez Y (2008) Percepción de sobrecarga y nivel de burnout en cuidadores formales del adulto mayor institucionalizado. Enseñ Invest Psicolog 13(1): 127-142.

11. Vázquez García C, Esperón Ramón, González Losa M del R (2013) Síndrome de Burnout en cuidadores de adultos mayores que trabajan en casas de asistencia social. Rev Invest Clin 65(6): 510-514.

12. Aristizábal HGP, BlancoBDM, Sánchez RA (2013) El modelo de promoción de la salud de Nola Pender. Una reflexión en torno a su comprensión. Enf University ENEO UNAM 8(4): 16-23.

13. Flores GE, Rivas RE, Seguel PF (2012) Nivel de sobrecarga en el desempeño del rol del cuidador familiar de adulto mayor con dependencia severa. Cienc Enferm 18(1): 29-41.

14. Vicente RMA, de la Cruz GC, Morales NRA (2014) Cansancio, cuidados y repercusiones en cuidadores informales de adultos mayores con enfermedades crónicas degenerativas. Europ JInv Health Psychol Educ 4(2): 151-160.

15. Díaz AH, Lemus FNM, González CW (2015) Repercusión ética del cuidador agotado en la calidad de vida de los ancianos. Rev Cienc Méd 19(3): 478-490.

16. Rivera MH, Dávila MR, González APA (2011) Calidad de vida de los cuidadores primarios de pacientes geriátricos de la Clínica de Medicina Familiar Dr. Ignacio Chávez, ISSSTE. Rev Espec Méd-Quir 16(1): 27-32.

17. Alducin C, Coyote C, Muñoz A (2011) Estilo de vida promotor de salud y su relación con el consumo de tabaco en trabajadores de la industria. Tesis Univ Aut Querét Fac Enf, p. 1-42.

18. Firmino Bezerra ST, Mesquita Lemos A, Costa de Sousa SM, de Lima Carvalho CM, Carvalho Fernandesa AF, et al. (2013) Promoción de la salud: la calidad de vida en las prácticas de enfermería. Enferm glob 12(32): 260-269.

19. Candido MHC, Morais de Gouveia SA, Railka de Souza OA, Carolina Maria DLC, Maria Josefina DS et al. (2012) Sobrecarga y modificaciones de vida en la perspectiva de los cuidadores de pacientes con accidente vascular cerebral. Rev Latino-Am Enfermagem 20(5): 1-10.

20. Jofré AV, Sanhueza AO (2010) Evaluación de la sobrecarga de cuidadoras/es informales. Ciencia y Enfermería 16(3): 111-120. 
21. Palomé VG, Gallegos TRM, Xeque MAS, Alberto Juárez Lira y, María Guadalupe Perea Ortíz, et al. (2014) Nivel de sobrecarga en el cuidador principal del paciente crónico hospitalizado. Digital Ciencia @UAQRO, p. 1-10.

22. Pérez PM, Llibre RJJ (2010) Características sociodemográficas y nivel de sobrecarga de cuidadores de ancianos con Enfermedad de Alzheimer. Rev Cub Enf 26(3): 110-122.

23. Fernández AR, Manrique-Abril FG (2010) Rol de la enfermería en el apoyo social del adulto mayor. Enfermería Global 9(2): 1-9.

24. Pérez CV, Varela GRM, Martínez FB (2012) Familiares cuidadores de mayores: autopercepción de los cuidados. Zerbitzuan 52: 87-99.

25. Díaz NM, Díaz NM, Beristaín GI (2011)Proceso Enfermero basado en el Modelo de Promoción de la Salud. Desarrollo Cientif Enferm 19(4): 139-143.
26. Lucy Barrera Ortiz, Gloria M Carrillo González, Lorena Chaparro Díaz, Natividad P Afanador y Beatriz Sánchez Herrera (2011) Soporte social con el uso de TIC'S para cuidadores familiares de personas con enfermedad crónica. Rev Sal Públ 13(3): 446-457.

27. De Valle Alonso MJ, Hernández López IE, Zúñiga Vargas ML, Martínez Aguilera P (2015) Sobrecarga y Burnout en cuidadores informales del adulto mayor. Enferm Universit ENEO-UNAM 12(1): 19-27.

28. Menezes de Lucena Carvalho VA, Fernández Calvo Bernardino, Hernández Martín L, Ramos Campos Francisco, Contador Castillo I (2006) Resiliencia y el modelo Burnout-Engagement en cuidadores formales de ancianos. Psicothema 18(4): 791-796.

\section{Your next submission with Juniper Publishers will reach you the below assets}

- Quality Editorial service

- Swift Peer Review

- Reprints availability

- E-prints Service

- Manuscript Podcast for convenient understanding

- Global attainment for your research

- Manuscript accessibility in different formats

( Pdf, E-pub, Full Text, Audio)

- Unceasing customer service

Track the below URL for one-step submission https://juniperpublishers.com/online-submission.php 